\title{
O CURRÍCULO E O DESAFIO DA ABORDAGEM DA PRÁTICA SOCIAL NA EDUCAÇÃO PROFISSIONAL
}

\author{
Katia R. Koerich Fronza, Paula A. Grawieski Civiero, Fátima P. Zago de Oliveira \\ Instituto Federal Catarinense, câmpus Rio do Sul \\ Rio do Sul, Santa Catarina \\ E-mail: katiaf@ifc-riodosul.edu.br,paulaciviero@ifc-riodosul.edu.br, fatima@ifc-riodosul.edu.br
}

\author{
Walter A. Bazzo \\ Universidade Federal de Santa Catarina \\ Florianópolis, Santa Catarina \\ E-mail: wbazzo@emc.ufsc.br
}

Resumo: Neste artigo apresentamos uma discussão conjunta, oriunda das inquietações de um grupo que está preocupado com questões e com processos de identificação e definição da identidade curricular dos Institutos Federais de Educação, Ciência e Tecnologia (IFs), especialmente relacionada à Educação Profissional, que considere a realidade, a sociedade e as evoluções científicas e tecnológicas. Nosso objetivo é trazer à tona, para além dos aspectos teóricos e formais na educação profissional, uma discussão que envolva o enfrentamento das questões científicas, tecnológicas e sociais por meio do currículo. Muito se fala que o currículo deve ser ativo, deve proporcionar ao estudante a possibilidade de ser um cidadão crítico e atuante, comprometido com os reflexos que a ciência e a tecnologia trazem para a sociedade. Mas o currículo realmente dá conta disso? Vivemos em uma sociedade eminentemente capitalista, na qual o consumo, a competição e o individualismo são o foco principal. Como então falar em currículo voltado para a prática social? Ou ainda vamos mais longe: de qual prática social estamos falando?

Palavras-chave: educação profissional. currículo. prática social. ciência e tecnologia.

\section{THE CURRICULUM AND THE CHALLENGE OF APPROACH TO SOCIAL PRACTICE IN VOCATIONAL EDUCATION}

Abstract: In this article we present a joint discussion arising from the concerns of a group that is concerned with issues and processes of identification and definition of the curricular identity of the Federal Institutes of Education, Science and Technology (IFs), especially related to professional education, to consider the reality, society and scientific and technological developments. We aim to bring to the fore, in addition to theoretical and formal aspects in education, a discussion involving the face of scientific, technological and social issues through the curriculum. Much is said that the curriculum should be active, must give the student the opportunity to be a critical and active citizen, committed to the reflections that science and technology bring to society. But the curriculum gives really aware of it? We live in an eminently capitalist society in which consumption, competition and individualism are the main focus. How then talk about curriculum focused on social practice? Or go further: the social practice which we talking about?

Keywords: professional education. curriculum. social practice. science and technology.

Recebido em 18/08/2015. Publicado em 30/06/2016. 


\section{PRIMEIRAS PALAVRAS}

Afinal de contas, o que é currículo? Qual nossa visão de currículo? Nossa visão de currículo está mais preocupada com os referenciais teóricos ou com o que vivenciamos na prática social da/na escola e discussões contemporâneas? De que adiantam os conceitos teóricos que estão postos sobre currículo?

Partimos da certeza de que não é o currículo, sozinho, que dá conta de uma visão mais crítica sobre a sociedade, sobre os problemas que se apresentam decorrentes dos avanços científicos e tecnológicos. Pretendemos, então, expor nossas preocupações relacionadas às fragilidades do currículo no que diz respeito ao mundo contemporâneo, ao conhecimento reflexivo e à prática social. Procuraremos identificá-las e demarcar certa responsabilidade dos currículos sobre o desenvolvimento dessas temáticas. Ao mesmo tempo colocamos em dúvida se é somente ao currículo que cabe tal demanda.

Faremos essa discussão considerando três aspectos: o primeiro diz respeito à organização curricular de cursos de educação profissional decorrente do advento da implantação dos IFs (Institutos Federais de Educação Científica e Tecnológica); o segundo, à perspectiva da educação científica e tecnológica e; o terceiro, relacionado aos dois primeiros, que tange às práticas sociais decorrentes do viés curricular da perspectiva da educação científica e tecnológica na educação profissional ofertada pelos IFs.

É recorrente na educação de maneira geral e especificamente a partir da implantação dos IFs, os profissionais da educação desenvolverem todas as suas atividades (que não são poucas) com certa urgência, e, na efetivação e consolidação de políticas já postas, muito do que deveria acontecer acaba não acontecendo. É perceptível a falta de apoio, de estudos apropriados, de planejamento, de valorização dos profissionais e principalmente uma carência no comprometimento por parte dos órgãos educacionais.

No que diz respeito aos IFs, reforçamos ainda que estas instituições de ensino devem ter uma preocupação com a continuidade da formação voltada para a alfabetização científica e tecnológica que diga respeito ao enfrentamento e possível superação de mitos como tecnofobia, tecnofilia, tecnocracia, determinismo científico e tecnológico. 
Fronza, Civiero, Oliveira e Bazzo, 2016 - Diversidade e inclusão

[...] responder mais efetivamente aos anseios dessa sociedade, com a temperança necessária quanto à definição de suas políticas para que seja verdadeiramente instituição alavancadora de desenvolvimento com inclusão social e distribuição de renda (BRASIL, 2008, p. 25).

Entendemos que isso só é possível se houver a formação pautada em um conhecimento reflexivo dos professores, a valorização daqueles em processo de formação e daqueles já formados, superando o discurso romântico de que a educação é a salvação dos problemas sociais, mas entendendo que a educação hoje também se constitui num problema social.

No que tange à ciência e à tecnologia, é importante que assumamos definitivamente que elas fazem parte de nossas vidas e que devemos estar (ou sermos) preparados para perceber, de maneira crítica, como este processo interfere na organização social. O currículo escolar que supera a categorização dicotômica da teoria e da prática tem um papel fundamental neste aspecto, a concepção dos profissionais da educação e os fundamentos epistemológicos são também determinantes. Ousamos dizer, são esses, em detrimento daqueles que realmente podem possibilitar a superação.

\section{A CIÊNCIA E A TECNOLOGIA NO CURRÍCULO}

Os reflexos decorrentes dos avanços científicos e tecnológicos determinam a maneira de pensar, ser e agir das pessoas, consolidando-as inquestionavelmente no sistema capitalista do qual fazem parte. A afirmação de Bazzo (2010, p.103) de que "a lógica primordial do comportamento humano é a lógica da eficácia tecnológica; suas razões são as razões da ciência." ratifica a predominância de ciência e da tecnologia e a relação destas com a sociedade.

Uma vez que a ciência e a tecnologia têm esse vínculo indissociável com a sociedade, também têm com as atividades escolares manifestadas no currículo. Mas afinal, de qual currículo estamos falando? O que entendemos por currículo?

Ousaremos falar do currículo que acreditamos, ou seja, o currículo vivenciado pelos atores do processo educativo (profissionais da educação - educadores, e educandos). Estamos então falando de um currículo real, aquele que se origina da vivência, dos problemas que afetam o dia a dia de todos, da dependência que a tecnologia gera nestes cidadãos inseridos em uma sociedade 
de consumo, voltada para atender aos interesses de poucos e que tem como aliada uma ciência não neutra, que, assim como o currículo, é ideológica e carregada de intenções.

Entendemos então, por currículo, um artefato ideológico e político, que diz respeito aos interesses de grupos específicos e da sociedade como um todo, que pode libertar, mas que também pode alienar e dominar, assim como a ciência e a tecnologia.

Não sendo neutro, traz consigo uma série de valores e intencionalidades que contemplam necessidades e interesses próprios de segmentos específicos. Essa afirmativa é ainda mais relevante quando se consideram propostas que norteiam as diretrizes curriculares, que levam em conta a influência histórica do momento social, econômico e político, isto é, o cenário interfere nas mudanças.

O currículo, a ciência e a tecnologia servem também para reproduzir as organizações e classes sociais, em favor dos interesses da classe dominante. O currículo escolar não visa ao ideal utópico de formar cidadãos autônomos, é sim uma invenção social que implica numa seleção de cultura, de ênfases e omissões, determinado no campo político, fruto do jogo de poder, da luta de classes e das contradições. Ou seja, "o conhecimento corporificado no currículo é tanto o resultado de relações de poder quanto seu constituidor" (BORGES, 2008, p.18).

Compreendemos o currículo considerando o conhecimento vinculado aos aspectos sociais, econômicos, políticos e culturais, como conteúdos ensinados e aprendidos; formação e experiências dos sujeitos; planos pedagógicos de ensino organizados pelos professores em função de exigências do sistema escolar; objetivos propostos para serem alcançados no processo de ensinar e de avaliar.

E o currículo da educação profissional científica e tecnológica? Parece-nos que as orientações de determinação da organização do currículo da educação científica e tecnológica consideram a formação técnica e secundarizam as práticas e valores sociais, corroboram para a alienação e submissão do homem à ciência e à tecnologia.

O currículo reproduz e legitima a perspectiva social, científica, política e econômica instalada, “[...] é condicionado por essa pluralidade de imagens sociais que nos chegam de fora." (GONZÁLES ARROYO, 2008, p. 23); é determinado pelas forças econômicas e políticas ligadas a relações de 
poder na sociedade. As relações de poder podem ser imersas em uma organização curricular específica e, dependendo da maneira que se estabelece, podem favorecer para que o conhecimento tecnológico passe a predominar diante do conhecimento reflexivo.

Nesta perspectiva Skovsmose (2001, p. 31), na tese do currículo, afirma que "os princípios fundamentais da sua estruturação são derivados delas ou estão de acordo com as relações de poder dominantes na sociedade". Por isso propõe um currículo voltado à Educação Crítica (EC).

O axioma básico na EC é que a educação não deve servir como reprodução passiva de relações sociais existentes e de relações de poder. Esse axioma faz sentido quando falamos sobre competência crítica, distância crítica e engajamento crítico. A educação tem de desempenhar um papel ativo na identificação e no combate de disparidades sociais. Naturalmente, a educação não tem um papel importante nas mudanças sociais e tecnológicas - tais mudanças não são consequência de empreendimentos educacionais, mas a educação deve lutar para ter um papel ativo paralelo ao de outras forças sociais críticas (SKOVSMOSE, 2001, p. 32).

Nessa formulação, a EC é o movimento mais importante entre os que tentam negar a tese do currículo. A intenção da EC é desmascarar os princípios de estruturação dominantes do currículo como históricos acidentais.

Partindo da concepção que numa sociedade democrática todos tenham igual acesso à escolaridade e à aprendizagem, percebemos que a escola contempla a reprodução das estruturas sociais e dos valores tradicionais da cultura, em contradição com padrões democráticos da educação que deveriam reagir às diferentes maneiras pelas quais a sociedade se reproduz, contrabalanceando algumas dessas forças produtivas para prover uma distribuição equitativa do que a escola pode oferecer.

Podemos salientar que um dos objetivos da educação, decorrente do currículo, deve ser preparar para uma cidadania crítica visando, neste sentido, mais do que as condições técnicas para possibilitar a entrada no mercado de trabalho. 
Ao buscar tais necessidades, a sociedade se depara com o problema da democracia, criado pelo desenvolvimento de uma sociedade altamente tecnológica.

Diante disso, defendemos um currículo que dê aos sujeitos a possibilidade de interferência na vida em sociedade, que contribua para a formação do sujeito, a ponto deste humanizar seus pares e a sociedade. Um currículo que contribua para a emancipação do sujeito, que the dê condições de contribuir para a construção de uma sociedade menos individualista e mais coletiva; que permeie as dimensões da ciência e da tecnologia sem cair nos auspícios da tecnologização, com propósito, tendo características que se identificam com a discussão crítica. Um currículo que valorize o educar pela pesquisa (DEMO 1995), que valorize um ambiente de inquérito (POSTMAN E WEIGARTNER, 1972) tendo como fundamento a problematização constante da realidade local (FREIRE, 2014) e contemporânea, onde se valorize temas controversos.

Mas que tipo de currículo dá conta desta demanda? E será que é o currículo que dá conta dessa demanda no contexto científico, social, político e econômico no qual estamos inseridos?

Acreditamos que sozinho o currículo não dá conta de todas essas demandas. Entretanto cabe também a ele, consolidado na instituição social na escola, a responsabilidade de proporcionar aos sujeitos do processo educativo o conhecimento acerca das questões que permeiam o desenvolvimento social e as consequências decorrentes desse avanço, especialmente aqueles que dizem respeito à evolução da ciência e tecnologia.

Assim, é importante examinar com atenção as relações que se estabelecem entre o currículo, a ciência e a tecnologia, o trabalho e o papel dos IFs, motivo pelo qual é essencial intensificar a interação curricular para que o currículo não se degenere em uma das maneiras mais importantes de socializar os educandos em uma sociedade tecnológica e, ao mesmo tempo, destruir a possibilidade de se desenvolver uma atitude crítica em direção a essa sociedade tecnologizada. É fundamental que o currículo interaja com assuntos relacionados à ciência e tecnologia para que não seja dominado e transformado em um instrumento do desenvolvimento tecnológico e se torne um aparato sem crítica.

E se há crítica, é importante questionar sob qual perspectiva ela acontece. Para isso o currículo deve abarcar as questões novas, recentes e atuais. Muitas vezes é possível perceber que a ideia de 
'desenvolver' o senso crítico, muitas vezes, está relacionada ao estudo de um resumo qualquer que fale de um assunto qualquer, considerado supostamente contemporâneo. O termo crítico e reflexivo, deve vir acompanhado sempre de algo que possibilite uma leitura e uma intervenção do e sobre a realidade.

Isso nos leva a defender que a perspectiva crítica deve estar presente na concepção e constituição do currículo, para que este não seja mais um mecanismo de domesticação do ser humano em uma sociedade cada vez mais impregnada de tecnologia. Que não seja apenas mais uma burocracia e nem crie burocracias. Um currículo que apenas cumpre uma exigência burocrática administrativa pedagógica pode se transformar numa arma poderosa que rompe com a possibilidade de uma aprendizagem humanizadora.

Nesse sentido é possível corroborar com Postman e Weigartner (1972, p.201), ao afirmarem que "A tecnologia educacional faz sentido, unicamente, para ajudar os aprendizes a aprender estratégias de sobrevivência num mundo de mudança".

Desta forma a ciência e a tecnologia transcendem a ideia de impregnação e se tornam constituidoras da prática curricular e da vida das pessoas.

\section{OS IFS: POSSIBILIDADES CURRICULARES EM PRÁTICAS SOCIAIS?}

Conhecemos o discurso de que o currículo tradicional não dá conta de cumprir com o papel social da escola pública e este discurso continua forte entre os profissionais da educação. Nas palavras de Silva $(2004$, p. 21) nos dias de hoje, "[...] já se tornou um perigoso lugar comum. Teoria e prática absolutamente dissociadas [...] passou a ser uma constatação tão passivamente aceita pela comunidade escolar que sua concretude é concebida como intrínseca ao cotidiano educativo".

O currículo escolar na Educação Profissional ainda valoriza e enfatiza, sobremaneira, a inserção no "mercado de trabalho". De acordo com o Presidente do Instituto de Pesquisa Econômica Aplicada (Ipea), Marcio Pochmann, em entrevista ao Portal Aprendiz, não se deve subordinar a educação às exigências do mercado de trabalho, pois essas exigências são, de maneira geral, de curto prazo. Além disso, a subordinação e a alienação tiram da escola a perspectiva educadora, uma vez que se deve considerar que, além do trabalho, a ação educativa deve contemplar a vida social. A 
construção de uma sociedade melhor está para além da demanda da economia, e deve ser pautada na capacidade dialógica dos sujeitos.

Ou seja, o currículo vigente se preocupa com a estrutura confortável do passado, não com as mudanças velozes que a sociedade contemporânea requer, nem com a formação de quem questiona constantemente e busca respostas para os problemas que surgem.

Linsingen (2006) afirma que se faz necessário criar condições curriculares que abordem uma perspectiva transformadora em que seja considerada, efetivamente, a real construção da sociedade. Segundo Cunha e Borges (2001, p. 44-45) citados por Linsingen (2006, p. 8) "uma abordagem do currículo que permanece submissa à primazia do mercado pode reduzir o projeto educacional a um sistema de treinamento de pessoas".

Contrapondo-se a essa ideia, ratifica-se que o currículo deva considerar, além de aspectos técnicos, os significados sociais, culturais, ambientais e éticos, não atendendo a lógica da produção mercantilista competitiva, mas procurando "[...] um maior equilíbrio nas relações sociais e contribuindo para a ampliação das igualdades socioeconômicas" (LINSINGEN, 2006, p. 8).

Isso requer que o currículo rompa a lógica de repetição de conceitos arcaicos como os de: verdade absoluta, certeza, identidade isolada, causalidade simples, de que diferenças existem apenas em efeitos paralelos e opostos. Conhecimento dessa natureza gera atitude passiva e de aceitação das imposições postas pelo sistema social dominante.

Na educação ofertada pelos IFs é possível, através do currículo, garantir uma flexibilidade de formação dos diferentes níveis da educação básica e do ensino superior, da educação profissional e tecnológica.

Na proposta dos Institutos Federais, agregar à formação acadêmica a preparação para o trabalho (sem deixar de firmar o seu sentido ontológico) e a discussão dos princípios e tecnologias a ele concernentes dá luz a elementos essenciais para a definição de um propósito específico para a estrutura curricular da educação profissional e tecnológica: uma formação profissional e tecnológica contextualizada, banhada de conhecimentos, princípios e valores que potencializam a ação humana na busca de caminhos mais dignos de vida (BRASIL, 2008, p. 28). 
A esta proposta é essencial colar a discussão sobre a preparação para o mundo do trabalho, do qual os princípios científicos e tecnológicos não podem ficar desconectados de uma discussão humanizadora, em busca da equidade social. Se isto não for questionado poder-se-á cair em um arcabouço mercadológico onde o currículo torna-se parte do processo de mercantilização da educação. Processo este contraposto por muitos professores e pesquisadores do mundo todo, ao exigirem entre outros pontos, a

necessidade de trabalhar de maneira renovada para garantir o direito humano à educação para todos e todas, a educação pública, gratuita e de qualidade para todos e todas, assim como a recuperação de uma perspectiva da educação guiada pelas ciências pedagógicas e não pelas lógicas do mercado (INSTITUTO HUMANITAS UNISINOS, 2015).

A proposta curricular dos IFs, enquanto instituição pública e gratuita, lida com o conhecimento de forma integrada e verticalizada. A proposta pedagógica se mostra pautada na superação da dicotomia ciência/tecnologia e teoria/prática, ruptura do currículo hermético, do tratamento do conhecimento de forma descontextualizada dos aspectos sociais, culturais, ambientais e econômicos, propondo um currículo, segundo Chomsky (2011), que diga não ao doutrinamento sócio educacional.

Nesse sentido, os IFs têm o compromisso e podem sim tornar o currículo uma prática social. Romper com a estrutura da organização por disciplinas, reestruturando-a por áreas, fundamentado na necessidade do questionamento reconstrutivo como atitude cotidiana no professor e no aluno, distanciando-se do cardápio de meras aulas (Demo, 2011). Esta é uma possibilidade e um desafio.

Por isso, a viabilidade de uma nova organização curricular pode ter como pressuposto o refinamento de concepções dos atores - coordenação pedagógica, docentes, pedagogos, representação da comunidade escolar, dentre outros. A questão colocada aqui passa pela formação das coordenações e dos professores envolvidos no processo. Infelizmente, na seleção de professores para comporem o quadro docente dos IFs, existe a confusão de que a qualidade de um professor se dá em função dos títulos. Muitos doutores ao adentrarem numa sala de aula vivem intricados em didáticas tradicionais ou meramente repassadoras de informações. Por isso, 
uma mudança na estrutura curricular dos IFs pressupõe a participação de todos em discussões fundamentadas em princípios críticos, abertas e decisórias.

Isso está atrelado à formação dos professores. É fundamental que os professores conheçam as controvérsias dos temas contemporâneos e possam tecer leituras e opiniões críticas, tornando-se capazes de produzir seus próprios textos, de tornarem-se pesquisadores e não meros reprodutores de conhecimentos.

Dessa forma, o envolvimento coletivo dos distintos sujeitos do processo educativo, conduz a uma elaboração cooperativa, de modo que as concepções de observação e experiência, através de práticas e conhecimentos compartilhados por um grupo que possa associar prática ao currículo.

Silva, em sua tese, constata que,

A superação com a prática exige tomá-la como objeto de criticidade coletiva, o que requer um distanciamento epistemológico e problematizador, uma conscientização política das intencionalidades, sendo esses os balizadores concretos da prática criativa de um currículo participativo. Não há participação sem a voz, a ação e a decisão dos envolvidos, sem políticas pedagógicas que a efetivem. A participação não pode ser decretada, pode ser construída somente com a unidade escolar (2004, p. 23).

Queremos explicitar que uma condição essencial para a prática de um currículo que busca garantir a formação social e crítica do cidadão é a ação e a formação do professor. Um currículo, elaborado com distanciamento dos atores que o irão colocar em prática, não contribui para a mudança de concepções. Por isso, as mudanças curriculares não devem ocorrer de maneira brusca e imposta, mas de maneira processual, gradativa e com construção coletiva, envolvendo a equipe pedagógica.

É a construção coletiva que pode permitir ou provocar a mudança de concepções do indivíduo e o seu compromisso com currículo e prática.

A perspectiva de uma proposta ousada, determinada por eixos pedagógicos e flexibilidade de áreas de conhecimento, pode ser alternativa para um currículo que rompa com o doutrinamento 
sócio educacional e agregue discussões e reflexões que levem a ações e promovam transformações na prática social.

\section{PRÁTICA SOCIAL OU DOUTRINAMENTO SÓCIO EDUCACIONAL?}

O currículo ainda serve para a doutrinação e servidão às grandes corporações, e manutenção de desigualdades sociais. Isto sugere o desafio da inserção curricular de temas que se orientem por um enfoque que articule aspectos relacionados à ciência, à tecnologia e à sociedade.

Mas será que cabe apenas ao currículo a responsabilidade pelo enfoque social? Dará ele conta, por si só desta demanda? A estes questionamentos acrescentamos outro que denota a necessidade da formação dos profissionais da educação, enfatizando a definição de concepções (mundo, educação, escola, sujeito, currículo, etc.) que norteiam a organização curricular: $A$ concepção filosófica dos docentes tem alguma interferência? Faz diferença?

Ainda mais, o que é essencial no currículo para despertar a preocupação com as interferências do enfoque científico e tecnológico na sociedade voltado para as práticas sociais e subversão da ordem do doutrinamento sócio educacional? Quais projetos de intervenção podem ser desenvolvidos no currículo de forma a serem motivadores do processo de mudança social?

Diante de tantos questionamentos vinculados às mudanças de práticas curriculares, percebemos que a resposta se pauta no silêncio, que os professores se escondem atrás da matriz curricular. Certo comodismo e conformismo se estabelecem no momento em que "não está na matriz, então não trabalho; ou, não trabalho porque não dou conta, mesmo que esteja na matriz". É importante discutir percepções e aproximar concepções; envolver os sujeitos no processo pedagógico, especialmente no que diz respeito à concepção filosófica; relacionar o que se quer como prática social, pautada por um currículo crítico.

Nesta perspectiva, a inserção de enfoques que relacionam ciência e a tecnologia com a sociedade (CTS) é uma possibilidade, por considerarem a relação das questões tecnológicas e humanas, além de promover a alfabetização científica e tecnológica.

CTS tem por finalidade promover a alfabetização científica e tecnológica, mostrando a ciência e a tecnologia como atividades humanas de grande importância social, embora não determinantes. [...]. Trata também de estimular e consolidar 
nos jovens o interesse pelos estudos da ciência e da tecnologia, mostrando com ênfase a necessidade de um juízo crítico e de uma análise reflexiva das suas interferências na sociedade (BAZZO, PEREIRA e LINSINGEN, 2008, p. 162).

Um currículo organizado com este enfoque dá aos estudantes, de todos os níveis de ensino que envolve ciência e tecnologia, condições de refletir e interferir nos problemas sociais, além de favorecem:

[...] o desenvolvimento e a consolidação de atitudes e práticas democráticas nas questões de importância social relacionadas com a inovação tecnológica [...] contribuir para uma eliminação do crescente abismo que se consolidou entre a cultura humanista e a cultura científico-tecnológica, que tanto fragmenta a nossa sociedade. (BAZZO, PEREIRA e LINSINGEN, 2008, p. 162).

A ideia de levar para sala de aula o debate sobre as relações existentes entre ciência, tecnologia e sociedade - [...] - vem sendo difundida por meio dos Parâmetros Curriculares Nacionais (PCNs) como forma de Educação Tecnológica, a qual não seria voltada para confecção de artefatos, mas para a compreensão da origem e do uso que se faz desses artefatos e também mentefatos na sociedade atual (PINHEIRO, SILVEIRA e BAZZO, 2007, p. 75).

Além disso, currículos organizados nessa perspectiva, segundo Cutcliffe (1990), citado por Bazzo, Linsingen e Pereira (2003, p. 144),

[...] também pretendem que a alfabetização contribua para motivar os estudantes na busca de informação relevante e importante sobre as ciências e as tecnologias da vida moderna, com a perspectiva de que possam analisá-la e avaliá-la, refletir sobre essa informação, definir os valores implicados nela e tomar decisões a respeito, reconhecendo que sua própria decisão final está inerentemente baseada em valores.

Para que isso ocorra, o doutrinamento curricular sócio-educacional, que diz respeito à visão mercantilizada do currículo, deve ser substituído pela articulação curricular, que consiste em considerar o desenvolvimento e aprendizagens sociais. Ou seja, um currículo crítico. 


\subsection{O que é essencial estar presente no currículo para despertar a preocupação com as interferências com enfoque científico e tecnológico na sociedade}

Um currículo crítico, construído coletiva e cooperativamente, revela princípios carregados de valores, não neutros. Questões relacionadas com um currículo crítico ligam-se ao seguinte:

A aplicabilidade do assunto: quem o usa? Onde é usado? Que tipos de qualificação são desenvolvidos?

Os interesses por detrás do assunto: que interesses formadores de conhecimento estão conectados a esse assunto?

Os pressupostos por detrás do assunto: que questões e que problemas geraram os conceitos e os resultados? Que contextos têm provido e controlado o desenvolvimento?

As funções do assunto: que possíveis funções sociais poderiam ter o assunto? Essa questão não se remete primariamente às aplicações possíveis, mas a função implícita [...] nas atitudes relacionadas a questões tecnológicas, nas atitudes dos estudantes em relação a suas próprias capacidades etc.

As limitações do assunto: em quais áreas e em relação a que questões esse assunto não tem qualquer relevância? (SKOVSMOSE, 2001, p. 19)

Após a leitura destes pontos surgem outros questionamentos: ao organizar e discutir o currículo nos IFs são feitas tais indagações? Até que ponto estamos preparados para questionamentos no sentido de construirmos um currículo crítico? Qual o comprometimento com a relevância social dos conteúdos programáticos? As indagações são muitas e as respostas nem sempre são claras. Cabe sairmos da comodidade de currículos prontos e passarmos a discuti-los sob enfoques críticos.

A esse respeito Silva (2004, p. 18) afirma que,

Uma educação crítica e libertadora concebe o currículo como o conjunto de práticas socioculturais que - de forma explícita ou implícita, consciente, intencional, empírica ou incorporada inconscientemente - se inter-relacionam nas diferentes instâncias e momentos do espaço-tempo escolar. Assume-se a defesa de uma intervenção pedagógica crítica na prática educativa desumanizadora vigente, na perspectiva de um currículo responsável, comprometido com os 
Fronza, Civiero, Oliveira e Bazzo, 2016 - Diversidade e inclusão

socialmente excluídos, que parta das necessidades e dos conflitos vivenciados para tornar-se significativo, crítico, contextualizado, transformador e popular.

\subsection{Quais projetos de intervenção podem ser desenvolvidos no currículo como motivadores do processo de mudança social}

Os conteúdos que se incorporam à realidade da escola têm o potencial de abordar elementos fundamentais da aprendizagem em ação. Assim, entendemos da mesma forma que Civiero (2009) que não basta a transposição dos saberes, é preciso que a transposição seja reflexiva, de modo a representar um movimento importante na direção de uma sociedade democrática.

Em situações como essas, a preocupação com o currículo é inevitável. Afinal, ao propor as investigações, o professor tem em mente os tópicos que ele pretende explorar. Além disso, os caminhos para a problematização foram também por ele indicados.

Entretanto, mesmo assumindo como objetivo a aprendizagem do conteúdo, ficam assegurados os componentes de criticidade: currículo, engajamento e reflexão. Fruto do trabalho investigativo realizado e que fez surgir, além do conhecimento específico, descobertas, questionamentos, discussões, reflexões sobre os resultados e sobre os seus significados, de modo a proporcionar o conhecimento das realidades relacionadas com as situações envolvidas.

Para que o currículo possa ser um motivador e um condutor no processo de mudança social, é necessário que haja mudanças na sua estrutura. Os conteúdos não podem ser organizados linearmente, tampouco em gavetinhas, fragmentado, como se um conteúdo não tivesse interconexão com o outro. Por isso, o desenvolvimento dos conteúdos deve primar pela investigação, pela pesquisa e pela problematização constante, na dimensão dialógica da produção do conhecimento.

É fundamental que a organização curricular esteja em constante movimento, de modo a superar a fragmentação do conhecimento do paradigma disciplinar, que reproduz a visão positivista e focar a produção do conhecimento em rede, que supera os processos de transmissão lineares, tornando-se uma ferramenta educacional que contribui na organização de experiências e efetivação de práticas. 


\section{ALGUMAS CONSIDERAÇÕES}

Para se conceber um currículo que reconheça o conhecimento reflexivo vinculado à prática social há necessidade que ele seja aberto, que flexibilize a estruturação dos conteúdos programáticos, que rompa com a linearidade e com os pré-requisitos que impedem a discussão de um tema porque não está na "pauta", na "ordem da vez".

Neste viés precisamos, mais do que um currículo em espiral, um currículo que dê abertura para desenvolver investigações, para entender a pesquisa como princípio educativo e formador de habilidades e atitudes de questionamentos, de tomada de decisões. Para Demo (1995, p.61), “a pesquisa é hoje a base indispensável da competência profissional" e permite o delineamento de conhecimentos desenvolvidos de acordo com a necessidade e não por imposição de planos ou grades (matrizes).

Almejamos um currículo que apresente uma estrutura com base no questionamento, no desenvolvimento de temas controversos e contemporâneos, que coloque em xeque os mitos da ciência e tecnologia, que conecte o desenvolvimento científico e tecnológico ao desenvolvimento humano, social, econômico, cultural. Nesta perspectiva, é possível romper com o doutrinamento sócio educacional? É possível articular o currículo com interesses voltados para a transformação social?

Confrontos ideológicos serão estabelecidos e a articulação entre teoria e prática será colocada à prova. Educadores e educandos com atitudes de questionamento buscarão novas fontes de discussão, motivados pelas necessidades contemporâneas. Discussões que permeiam a educação crítica discorrem sobre a emancipação humana, conseguida pelo sujeito transformador de sua realidade.

Sabemos que isso é possível a partir da organização de um currículo que tenha elementos que mostrem a necessidade da constituição de um sistema diferente do que está posto. Um sistema para além do capital, que continua reproduzindo e "formando" (no sentido de colocar na forma) sujeitos para dar continuidade ao capitalismo ou servir a ele.

Quando articulamos a educação e o mundo do trabalho nos confrontamos com a necessidade desta emancipação, identificando o quanto somos explorados ou exploradores pelo/do sistema. 
No entanto, para defender uma educação, pautada num currículo para além destas imposições há que questionarmos para que, o porquê e para quem ensinar e, após essa digressão, estaremos aptos a entender o quê e como ensinar.

Assim, a discussão de um currículo pautado na prática social demanda constantes reflexões, seguidas de análise e propostas de ações que levem a mudanças, pois o discurso não muda relações sociais, o que muda é a tomada de decisão e a ação.

Um currículo construído na ação se expande e integra o processo de (re)construção de todo contexto e cultura inerente à sociedade imersa na tecnologia produzida pela globalização, resignificando a atribuição e representação dos conteúdos registrados, vai se integrando como prática social e deixa de ser apenas mais um aparato de domesticação e reprodução de determinadas relações sociais de poder.

O desenho curricular precisa ter um diferencial e o professor precisa dar conta deste diferencial. O professor só dará conta se participar do processo, se tiver acesso a temas controversos, se sentir a necessidade de construir o novo currículo.

Se isso não acontecer, cada qual continua com sua compreensão de mundo e continua reproduzir o currículo na sua perspectiva e não numa perspectiva coletiva e comum, que pode ser crítica ou não. Assim, a grade (matriz), que infelizmente é um dos únicos aspectos observados pelo professor que estão vinculadas ao 'como' do currículo, pode ser constituída de um novo formato, um novo designer, pautado em concepções filosóficas consolidadas, que instiguem e proporcionem ao professor as mudanças e avanços necessários à prática social crítica. Questões relativas ao "como" do currículo são importantes, porém elas só adquirem sentido numa perspectiva que as considere em sua relação com questões que perguntem pelo "por que" das formas de organização do conhecimento escolar.

Este pode ser um caminho para inserir a discussão e, mais adiante, provocar uma mudança na postura crítica e social, levando a mudanças na prática docente. É possível ir além? Documentos curriculares sinalizam para essa perspectiva, entretanto, acontece em sala de aula? É possível provocar desconforto e sair da linearidade excessiva? Que forças fazem com que o currículo seja hegemônico e que planejam e se utilizam do currículo para produzir identidades sociais que 
ajudam a prolongar as relações de poder existentes? Como deixar de culpar o currículo, os livros didáticos, os instrumentos e metodologias para assumir as responsabilidades decorrentes da (falta) de uma concepção filosófica para além do tradicional? Apontamos ainda possíveis controvérsias curriculares que deformam o papel do currículo: A prática social não acontece porque não está explicitamente contemplada no currículo? É o currículo que tem que dar conta desta inserção? Ou o currículo está sendo usado como desculpa para que a práxis não aconteça?

É uma missão quase utópica e árdua - mudar concepções e práticas pedagógicas tradicionais extremamente consolidadas. Estamos num caldeirão que ferve do jeito que a sociedade determina. Estamos num jogo de poder, num jogo de contra corrente. Onde é preciso remar com força contra a manutenção do status quo em busca de uma educação que prime à equidade social.

\section{REFERÊNCIAS}

BAZZO, Walter Antonio. Ciência, tecnologia e sociedade e o contexto da educação tecnológica. Florianópolis: Editora da UFSC, 2010d

BAZZO, Walter Antonio; LINSINGEN, Irlan von; PEREIRA, Luiz T. do Vale. Introdução aos estudos CTS (Ciência, Tecnologia e Sociedade). Madri: OEI, 2003.

BAZZO, Walter Antonio; PEREIRA, Luiz T. Do Vale; LINSINGEN, Irlan von. Educação tecnológica: enfoques para o ensino de engenharia. Florianópolis: Editora da UFSC, 2008.

BRASIL. MEC/SETEC. Institutos Federais de Ciência, Educação e Tecnologia: concepção e diretrizes. 2008. Disponível em: <portal.mec.gov.br/setec/arquivos/pdf3/ifets_livreto.pdf>. Acesso: 10 mar. 2010.

BORGES, Maria da Ressurreição Coqueiro. Concepções Educacionais e Currículo (Módulo). Vila Velha: ESAB, 2008.

CIVIERO, P. A. G. Transposição Didática Reflexiva. Dissertação (Mestrado em Ensino de Matemática). Porto Alegre: UFRGS, 2009.

CHOMSKY, Noam. A escola como instrumento de controle e coerção. Disponível em: <resistir.info/varios/chomsky_educacao.html>. Acesso em: 21/06/2011.

DEMO, Pedro. Educar pela pesquisa. 9.ed. Campinas: Autores Associados, 2011. (Coleção educação contemporânea)

ABC: iniciação à competência reconstrutiva do professor básico. Campinas, SP: Papirus, 1995. (Coleção magistério: Formação e trabalho pedagógico)

FREIRE, Paulo. Pedagogia do oprimido. São Paulo: Paz e Terra, 2014.

GONZÁLES ARROYO, Miguel G. Indagações sobre Currículo: Educandos e Educadores: seus direitos e o currículo. Organização do documento Jeanete Beauchamp, Sandra D. Pagel, Aricléia R. Do Nascimento. Brasília: Ministério da Educação, Secretaria da Educação Básica, 2008.

INSTITUTO HUMANITAS UNISINOS. Docentes e pesquisadores de todo o mundo escrevem carta à UNESCO reclamando da mercantilização da educação. Disponível em: <ihu.unisinos.br/noticias/544698-docentes-e- 
pesquisadores-de-todo-o-mundo-escrevem-carta-a-unesco-reclamando-da-mercantilizacao-da-educacao>. Acesso em 12 ago. 2015.

LINSINGEN, Irlan Von. CTS na educação tecnológica: tensões e desafios. Mesa 4. I Congresso Iberoamericano de Ciencia, Tecnología, Sociedad e Innovación CTS + I. Palacio de Minería. 19 a 23 de Junio de 2006.

PINHEIRO, Nilcéia Aparecida Maciel; SILVEIRA, Rosemari Monteiro Castilho Foggiatto; BAZZO, Walter Antonio. Ciência, tecnologia e sociedade: A relevância do enfoque CTS para o contexto do ensino médio. Ciência \&Educação, v. 13, n. 1, p. 71-84, 2007.

POSTMAN, Neil; WEINGARTNER, Charles. Contestação: nova fórmula de ensino. Editora Expresso e Cultura, Rio de Janeiro, 1972.

SILVA, Antonio Fernando Gouvêa da. A construção do currículo na perspectiva popular crítica: das falas significativas às práticas contextualizadas. São Paulo, 2004. 539 f. Tese (Doutorado - Programa de Pós-Graduação em Educação: Currículo) Pontifícia Universidade Católica de São Paulo.

SKOVSMOSE, O. Educação matemática crítica: a questão da democracia. Campinas: Papirus, 2001. 